\title{
Spatial Firing of Hippocampal Place Cells in Blind Rats
}

\author{
Etienne Save, Arnaud Cressant, Catherine Thinus-Blanc, and Bruno Poucet \\ Centre for Research in Cognitive Neuroscience, Centre National de la Recherche Scientifique, 13402 Marseille \\ Cedex 20, France
}

\begin{abstract}
The rat hippocampus contains cells that are characterized by location-specific firing. Previous work has shown that the angular position of hippocampal place cell firing fields is accurately controlled by the position of visual cues, suggesting that vision plays a important role in triggering place cell activity. However, a role for other types of information has also been suggested because place cell activity can be recorded while animals are moving in the darkness. In this study, we asked whether place fields can get established in rats that have never
\end{abstract}

seen their environment. We studied place cell activity in early blind rats and found that these rats had place cells very similar to those recorded from sighted rats. This result suggests that early vision is not necessary for normal firing of hippocampal place cells. Dynamic, motion-related information in conjunction with stimulus recognition seems to be sufficient.

Key words: hippocampus; unit recordings; place cells; spatial learning; spatial memory; vision; path integration; rat
One of the most intriguing features of the rat hippocampus is the existence of place cells. First discovered by O'Keefe and Dostrovsky (1971), such cells, when recorded extracellularly from a freely moving rat, have the remarkable characteristic of being active only when the animal is in a specific region of its environment. Thus, a given place cell fires in a spatially delimited area called the place (or firing) field (O'Keefe and Nadel, 1978; Muller, 1996). Together with the well documented impairments in navigational abilities after lesions of the hippocampus, the existence of place cells provides strong evidence of some important contribution of the hippocampus to the processing of spatial information (O'Keefe and Nadel, 1978; see also Nadel, 1991; Poucet, 1993; Poucet and Benhamou, 1997).

For the last 20 years, the nature of the sensory information that triggers the firing of place cells has been a topic of considerable interest. Previous work has shown that the location of the place fields can be controlled by visual landmarks (Hill and Best, 1981; Muller and Kubie, 1987; O'Keefe and Speakman, 1987). For example, when a single white cue card attached to the wall of a recording cylinder is rotated, fields rotate equally, suggesting that place cell firing is under the control of visual cues (Muller and Kubie, 1987). Nevertheless, place field positions may also stay stable for some time when relevant visual cues are removed or the room lights are switched off (Muller and Kubie, 1987; O'Keefe and Speakman, 1987; Quirk et al., 1990), thus suggesting that place cells also use nonvisual information to fire in relation to the location of the animal in space.

\footnotetext{
Received Oct. 1, 1997; revised Dec. 4, 1997; accepted Dec. 8, 1997.

This work was supported by the Centre National de la Recherche Scientifique and by Centre National de la Recherche Scientifique/National Science Foundation Grant 96/0690 and NATO Collaborative Research Grant 940777. We thank B. Arnaud and E. S. Hawley for help in constructing various parts of the unit recording system and L. Eberle and R. Fayolle for electronics. We are grateful to A. Fenton, C. Kentros, R. U. Muller, M. Stead, and S. Wiener for helpful discussions and suggestions. Parts of this paper have been presented previously at the 25 th Annual Society for Neuroscience Meeting.

Correspondence should be addressed to Dr. Bruno Poucet, Center for Research in Cognitive Neuroscience, Centre National de la Recherche Scientifique, 31 chemin Joseph-Aiguier, 13402 Marseille Cedex 20, France.

Copyright (C) 1998 Society for Neuroscience $0270-6474 / 98 / 181818-09 \$ 05.00 / 0$
}

One type of information that has been suggested to trigger place cell activity in the absence of visual cues is motionrelated information (O'Keefe, 1976; Hill and Best, 1981; Quirk et al., 1990; Sharp et al., 1995; McNaughton et al., 1996). According to this hypothesis, the rat would update its position by keeping track of its movements in space based on signals stemming from the proprioceptive and vestibular systems as well as from motor efference copy (McNaughton et al., 1996). However, this strategy, known as path integration (Mittelsteadt and Mittelsteadt, 1980), tends to accumulate errors so that if no recalibration occurs, the cumulative error becomes so large that any further computation is hopeless (Mittelsteadt, 1983; McNaughton et al., 1991; Etienne et al., 1996; Gothard et al., 1996).

Although such calibration supposedly involves the gathering of information from many different sensory systems, it is often assumed that visual information plays a key role in this process (e.g., McNaughton et al., 1991). The emphasis on visual information probably occurs because vision allows for the simultaneous collection of a large amount of spatial information, thus enabling organisms to cope rapidly with the major features of their environment. As a result, current thinking about the information primarily used by the hippocampal place cell system puts strong emphasis on the visual system in one way or another. According to this view, one might expect that visual deprivation would induce profound disturbances of place cell activity. The present study tests this hypothesis by recording place cell activity from the hippocampus of rats made blind shortly after birth and thus never exposed to any visual stimulus. Place cell activity was recorded while rats were freely moving in a circular apparatus in which the only available cues were three-dimensional objects set at the periphery (Cressant et al., 1997). We found that hippocampal place cells recorded from blind rats were very similar to place cells recorded from sighted rats under the same circumstances, suggesting that visual information is not necessary for the spatial firing properties of place cells. 


\section{MATERIALS AND METHODS}

The methods were primarily the same as those used by Cressant et al. (1997), who showed that a set of three three-dimensional objects placed in the cylinder standing at the cylinder wall exerted control on the angular position of place fields.

Subjects. Single-unit recordings were obtained from 11 Long-Evans male rats born in the laboratory. Six rats underwent surgical removal of their eyes when they were 1 week old. Pups were separated from their littermates when they were 3 weeks old, at which time they were housed one per cage in a temperature-controlled colony $\left(20 \pm 2^{\circ} \mathrm{C}\right)$ on a natural light/dark cycle. Electrode implantation and screening for unit activity in both sighted and blind rats started when they were $\sim 90 \mathrm{~d}$ old and weighed between 300 and $350 \mathrm{gm}$. They had water ad libitum during all phases of the experiment. Before electrode implantation, the rats were fooddeprived to $85 \%$ of the ad libitum body weight and then trained in a "pellet-chasing" task for $10 \mathrm{~d}$ to permit estimation of positional firing rates everywhere in the cylinder. In this task, the rat had to retrieve 20 $\mathrm{mg}$ food pellets scattered into the cylinder. The pellets were delivered through an automatic food dispenser located $2 \mathrm{~m}$ above the cylinder. The dispenser was equipped with five small tubes through which the pellets could drop onto the floor. Because the food pellets landed in unpredictable places, the rat learned to run almost constantly over the whole floor surface. After training was complete, the rat visited the entire floor area in just a few minutes and so covered the accessible area several times during a 16 min recording session. The objects that were used during the recording were in place during the presurgery training period.

Apparatus. The recording apparatus was a gray cylinder $50 \mathrm{~cm}$ in height and $76 \mathrm{~cm}$ in diameter. The cylinder was visually isolated from the rest of the laboratory by a concentrically placed cylindrical curtain 250 $\mathrm{cm}$ in diameter and in height. The floor of the cylinder was a piece of gray paper that was replaced between recording sessions, so that olfactory cues were made irrelevant to the spatial position of the rat. During both screening and recording sessions, an FM radio tuned to a music broadcasting station was fixed to the ceiling in a central position relative to the cylinder to mask possible directional sounds. The rats were introduced into the recording cylinder from one of four equally spaced positions around the circumference. The entry position for a given session was chosen from a list of random numbers.

Three landmark objects were used. The objects differed from each other in color, size, shape, and texture. The objects were a black wooden cone (height, $25 \mathrm{~cm}$; diameter, $11 \mathrm{~cm}$ ), a white plastic cylinder (height, 25 $\mathrm{cm}$; diameter, $10 \mathrm{~cm}$ ), and a bottle of French red wine (height, $28 \mathrm{~cm}$; diameter, $9 \mathrm{~cm}$ ). Their locations relative to each other were fixed. Each was against the wall of the cylinder, forming an isosceles triangle, oriented with the cone at 12 o'clock, the bottle at three o'clock, and the cylinder at six o'clock.

Surgery. Surgery and care after the surgery were conducted according to institutional guidelines. One week after birth (i.e., before eye opening), six pup rats underwent surgical removal of their eyes under halothane anesthesia, after which they were returned to the cage of their mother. Electrode implantation in both sighted and blind rats was made when they were $90 \mathrm{~d}$ old. An injection of $0.3 \mathrm{ml}$ of atropine was given to prevent respiratory distress. Next, rats were anesthetized with pentobarbital $(45 \mathrm{mg} / \mathrm{kg})$ and placed in a Kopf stereotaxic apparatus. After a midline incision of the scalp was made, the skin and the muscles were retracted, and holes were drilled in the skull at appropriate locations. A movable array of $1025 \mu \mathrm{m}$ electrode wires (Kubie, 1984) was stereotaxically implanted in the dorsal hippocampus at the following stereotaxic coordinates: $3.8 \mathrm{~mm}$ posterior and $3.0 \mathrm{~mm}$ lateral to bregma and $1.5 \mathrm{~mm}$ below the dura (Paxinos and Watson, 1986). Miniature screws were placed over the right olfactory bulb, the left frontal cortex, and the left cerebellar hemisphere to anchor the headstage. To improve stability, an additional T-shaped screw was lowered upside down into the left parietal bone and turned $90^{\circ}$ before being tightened with a small nut. For protection from the dental cement, sterile petroleum jelly was applied to the exposed brain surface and the guide tubing of the electrode array. Dental cement was applied over the jelly and around the guide tubing. The exposed skull was covered with dental resin cement (Ivoclar). The screws and nut were then embedded in dental cement, and the bottoms of the assemblies of the three drive screws were cemented to the skull.

At the completion of the experiment, animals were killed with a lethal dose of pentobarbital and perfused intracardially with $0.9 \%$ saline followed by $4 \%$ formalin. Just before death, positive current $(15 \mu \mathrm{A}$ for 30 $\mathrm{sec}$ ) was passed through one of the microwires to deposit iron that could be visualized after reaction with potassium ferrocyanide (Prussian blue).
The brains were removed and stored for $1 \mathrm{~d}$ in $3 \%$ ferrocyanide. Later, frozen coronal sections $40 \mu \mathrm{m}$ in thickness were taken. Every fifth section was stained with cresyl violet for verification of electrode placements.

Recording methods. Beginning 1 week after surgery, the activity from each microwire was screened daily while the rat chased pellets in the cylinder. The electrodes were lowered over a period of several weeks while we searched for unit waveforms of sufficient amplitude to be isolated. Once a unit was isolated, it was recorded during several $16 \mathrm{~min}$ pellet-chasing sessions. Such multiple sessions are possible because the same cell can be reliably recorded for days or even weeks (Muller et al., 1987). This makes it possible to compare the firing of an individual cell after the environment has been changed many times.

Screening and recording were done with a cable attached at one end to a commutator that allowed the rat to turn freely. The other end of the cable was connected to a light-emitting diode (LED) for tracking the head position of the rat, a headstage with a field effect transistor amplifier (FET) for each wire, and finally a connector that mated with the electrode connector cemented to the skull of the rat. The FETs were used to amplify signals before the signals were led to the commutator via the cable. The fixed side of the commutator was connected to a distribution panel. From the panel, the desired signals were amplified 1000fold with low-noise differential amplifiers and were bandpass filtered from 0.3 to $10 \mathrm{kHz}$. The signals were then sent to two time-andamplitude window discriminators (model DIS-1; Bak Electronics) arranged in series for unit isolation. Accepted spikes were converted to digital pulses that were counted for $20 \mathrm{msec}$ intervals. At the end of each such interval [the end of a television frame (see below)], the spike count for one or more cells was sent as a four bit binary number to a computer.

The head position and head direction of the rat were tracked by locating two colored LEDs that were secured to the animal headstage. The red LED was positioned on the midline $\sim 1 \mathrm{~cm}$ above the head and somewhat forward of the eyes of the rat. The green LED, also on the midline, was set $\sim 5 \mathrm{~cm}$ behind the red LED. The two LEDs were independently tracked with a television-based digital spot follower that received the red and green RGB signals from a CCD color camera fixed to the ceiling of the experimental room. Each LED was detected in a grid of $256 \times 256$ square regions (pixels) $6.25 \mathrm{~mm}$ on a side, permitting a resolution of $\sim 6^{\circ}$ for head direction. For head position tracking, the resolution was reduced by two bits in each dimension, yielding a $64 \times 64$ grid of pixels $25 \mathrm{~mm}$ on a side. The $x$ and $y$ coordinates at the end of each frame were stored in parallel with the number of spikes counted during the $20 \mathrm{msec}$ frame.

Testing protocol. The 10 electrodes in each rat were checked several times a day while the rat was in the cylinder. If no cell could be isolated, the electrode bundle was advanced 25-50 $\mu \mathrm{m}$. Cells selected for recording were well discriminated complex-spike cells that showed clear location-specific firing. Activity from each microwire was screened daily while the rat was in the recording apparatus until unit waveforms of sufficient amplitude $(>80 \mu \mathrm{V})$ could be isolated. Once a unit was well isolated, several recording sessions were run consecutively to establish whether the positional firing patterns were controlled by the position of the set of object landmarks in the recording arena.

Before each session, the waveform and the firing pattern were inspected to check for constancy. Between sessions, rats were returned to their home cages, the objects were removed from the apparatus, and the floor paper in the cylinder was replaced. Next, the objects were placed at appropriate locations in the cylinder. The positions of the objects relative to each other were held constant so that the objects could act as reliable spatial cues.

Recordings were made first with the objects in a "standard" position relative to the laboratory frame and next with the objects rotated as a rigid set around the center of the cylinder. Usually, two sessions with the objects in the standard position were made. The purpose of these standard sessions was to ensure that the position of the place field of the cell was stable under constant conditions. If this was the case, a first "rotation" session was done during which the set of objects was rotated $90^{\circ}$ clockwise from the standard position. Finally, a second rotation session was conducted with the object set rotated $90^{\circ}$ counterclockwise back to the initial standard position.

Data presentation and analyses. To obtain a positional firing rate distribution, we accumulated the total time that the red light was detected in each pixel (dwell time) and the total number of spikes in each pixel for the session duration (usually $16 \mathrm{~min}$ ). The rate in each pixel was the number of spikes divided by the dwell time. Color-coded firing rate maps were used to visualize positional firing rate distributions. In such 
maps, yellow pixels represent locations in which the firing rate was exactly $0.0 \mathrm{~Hz}$ for the whole session. The highest firing rate category is coded as purple. Intermediate firing rates are shown as orange, red, green, and blue pixels (low to high). Pixels that were never visited during a session are encoded white. Because the in-field firing rates of place cells can vary over a large range, the values used as boundaries between color categories were autoscaled for the map of the first sessions recorded for a given cell. To permit comparisons among positional firing distributions across several sessions for a cell, we used rate categories for subsequent sessions that were the same as that for the first session.

To estimate numerically place field rotation between session pairs, we calculated a pixel-by-pixel cross-correlation as the positional firing pattern for the second session was rotated in $6^{\circ}$ steps relative to the positional firing pattern for the first session. That is, the pixel-by-pixel cross-correlation was calculated 60 times, at rotations of $0,6,12, \ldots 354^{\circ}$. The rotation associated with the highest correlation $\left(R_{\mathrm{Max}}\right)$ was taken as the rotation of the place field between the two sessions. Counterclockwise rotations were taken as positive; clockwise rotations were taken as negative. The difference between the observed rotation and the rotation expected if the angular field position were perfectly controlled by the stimulus ensemble was the estimate of rotation error for a pair of sessions. If the field rotated less than expected, the error was taken as negative; if the field rotated more than expected, the error was taken as positive.

A place field was defined as a set of at least nine contiguous pixels with a firing rate above the mean firing rate (i.e., above the total number of spikes during a recording session divided by session duration). Several numerical measures were used to describe the positional firing patterns. (1) In-field mean firing rate was the total number of spikes emitted by the cell while the rat was in the place field divided by the total time spent by the rat in this field. (2) In-field peak firing rate was the number of spikes emitted by the cell in the nine contiguous pixels of the place field associated with the most activity divided by the total time spent by the rat in these pixels. (3) Positional information content measured the amount of information (in bits) conveyed about spatial location by a single action potential emitted by a single cell (Skaggs et al., 1993) and was calculated according to the formula: $I=\Sigma_{i}\left(\lambda_{i} / \lambda\right) \times \log _{2}\left(\lambda_{i} / \lambda\right) \times P_{i}$. In this formula, $\lambda_{i}$ is the mean firing rate in each pixel, $\lambda$ is the overall mean firing rate, and $P_{i}$ is the probability of the animal to be in pixel $i$ (i.e., dwelling time in pixel $i$ /total dwelling time). The minimal value of positional information content is 0 for a cell the firing of which does not provide any information about location.

To obtain a directional firing rate distribution, we calculated the head direction of the animal from the relative coordinates of the red and green LEDs (Taube et al., 1990). Head direction analysis was performed at a resolution of $9^{\circ}$. The total time and the number of spikes discharged at each head direction for the session were summed from the collected samples. The directional firing rate of the cell was determined by dividing the total number of spikes in each head direction bin by the total time spent in the corresponding head direction bin. Because the recorded cells were place cells and thus had little if any directional selectivity, only a single measure was used to characterize their directional firing patterns. Directional information content (in bits) was calculated according to the formula: $I=\Sigma_{i}\left(\lambda_{i} / \lambda\right) \times \log _{2}\left(\lambda_{i} / \lambda\right) \times P_{i}$, where $\lambda_{i}$ is the mean firing rate in each $9^{\circ}$ head direction bin, $\lambda$ is the overall mean firing rate, and $P_{i}$ is the probability of the animal to face direction $i$.

\section{RESULTS}

\section{General characteristics of place cells in blind animals}

Place cells were first recorded during a session with the objects in a standard position. Figure 1 shows color-coded typical firing rate maps for place cells recorded from sighted and blind rats. Inspection of such maps shows that the positional firing properties of place cells in blind rats were very similar to those of place cells in sighted rats. This similarity was confirmed by the measure of positional information content (which characterizes the positional firing distribution) that yielded similar values for cells recorded from blind and sighted rats $(t=1.51$; df $=105$; NS; Table 1). Similarly, there was no statistically significant difference in place field size for cells recorded from blind and sighted rats $(t=1.67$; $\mathrm{df}=105 ; \mathrm{NS})$.

In contrast, place cells from blind rats were slightly more directional than were those from sighted rats as shown by the statistically significant difference in directional information content, a measure of the directional firing distribution $(t=2.74$; $\mathrm{df}=105 ; p<0.001)$. However, the very low values of directional information content $(<1.0)$ compared with the high values of positional information content suggest that the direction in which the head of the rat pointed was not an important factor of place cell firing in either sighted or blind rats. This was confirmed for place cells from blind rats by additional analyses that rely on the method of Muller et al. (1994). This method rests on the hypothesis that directional firing is accurately predicted from the direction-independent positional firing distribution and the fact that different portions of place fields tend to be visited with different heading directions. We therefore measured the directional firing rates of place cells predicted on the basis of these assumptions and compared them with the observed firing rates. As was found previously for hippocampal place cells in sighted rats (Muller et al., 1994), very strong agreement was found between predicted and observed firing rates for cells from blind rats (all correlations $>0.7$; df $=39$ ). This means that the directional selectivity observed in some cells was perfectly explained by the fact that the rats tended to enter the place field through stereotypic trajectories. This was particularly true for place fields near the wall that can be traversed only at restricted head directions. In short, in both sighted and blind rats, location was by far the strongest correlate of place cell discharge. Head direction alone or in combination with position was not an important predictor.

In contrast to the similarity in location-selective firing properties, place cells recorded from blind rats tended to discharge at considerably lower rates compared with place cells recorded from sighted rats. The firing rate of place cells in blind rats was lower according to the three estimates of unit firing (see Table 1),

\footnotetext{
Figure 1. Top. Firing rate maps for four place cells recorded from sighted rats (top) and eight place cells recorded from blind rats (middle and bottom). In each color-coded firing rate map, yellow represents locations in which the firing rate was $0.0 \mathrm{~Hz}$. The highest firing rate category is coded as purple. Intermediate firing rates are shown as orange, red, green, and blue pixels from low to high. Pixels that were never visited during a session are encoded white. The three landmark objects are indicated by the filled, gray, and open circles. For the cells recorded from sighted rats shown here, in-field peak firing rate $f($ in $\mathrm{Hz}$ ) and positional information content $P$ (in bits) were $f=7.4$ and $P=1.7(a), f=2.5$ and $P=1.5(b), f=15.4$ and $P=1.2(c)$, and $f=$ 2.7 and $P=2.7(d)$. For cells recorded from blind rats, in-field peak firing rate and positional information content were $f=9.6$ and $P=1.5(e), f=3.7$ and $P=1.7(f), f=5.4$ and $P=2.1(g), f=9.0$ and $P=2.2(h), f=8.2$ and $P=1.7(i), f=5.0$ and $P=2.3(j), f=3.2$ and $P=1.3(k)$, and $f=4.8$ and $P=1.5(l)$.

Figure 2. Bottom. Firing rate maps for two place cells from blind rats across four successive sessions. Rotation errors for Unit \#1 (top) were $-5^{\circ}\left(R_{\mathrm{Max}}\right.$ $=0.68)$ between sessions 1 and $2,-9^{\circ}\left(R_{\mathrm{Max}}=0.65\right)$ between sessions 2 and 3 , and $-2^{\circ}\left(R_{\mathrm{Max}}=0.56\right)$ between sessions 3 and 4 . Rotation errors for Unit \#2 (bottom) were $+7^{\circ}\left(R_{\text {Max }}=0.46\right)$ between sessions 1 and $2,-1^{\circ}\left(R_{\text {Max }}=0.49\right)$ between sessions 2 and 3 , and $+7^{\circ}\left(R_{\text {Max }}=0.40\right)$ between sessions 3 and 4 .
} 
SIGHTED

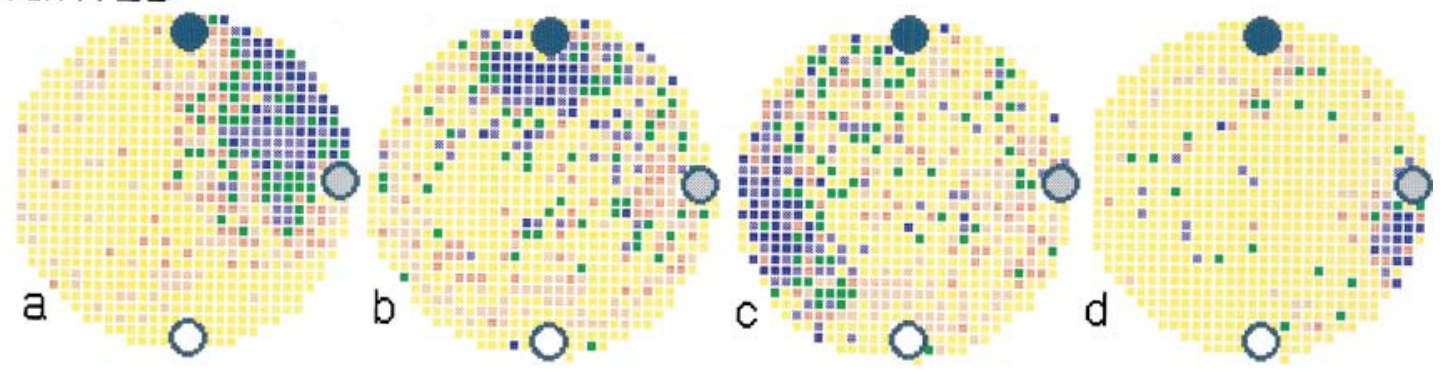

BLIND
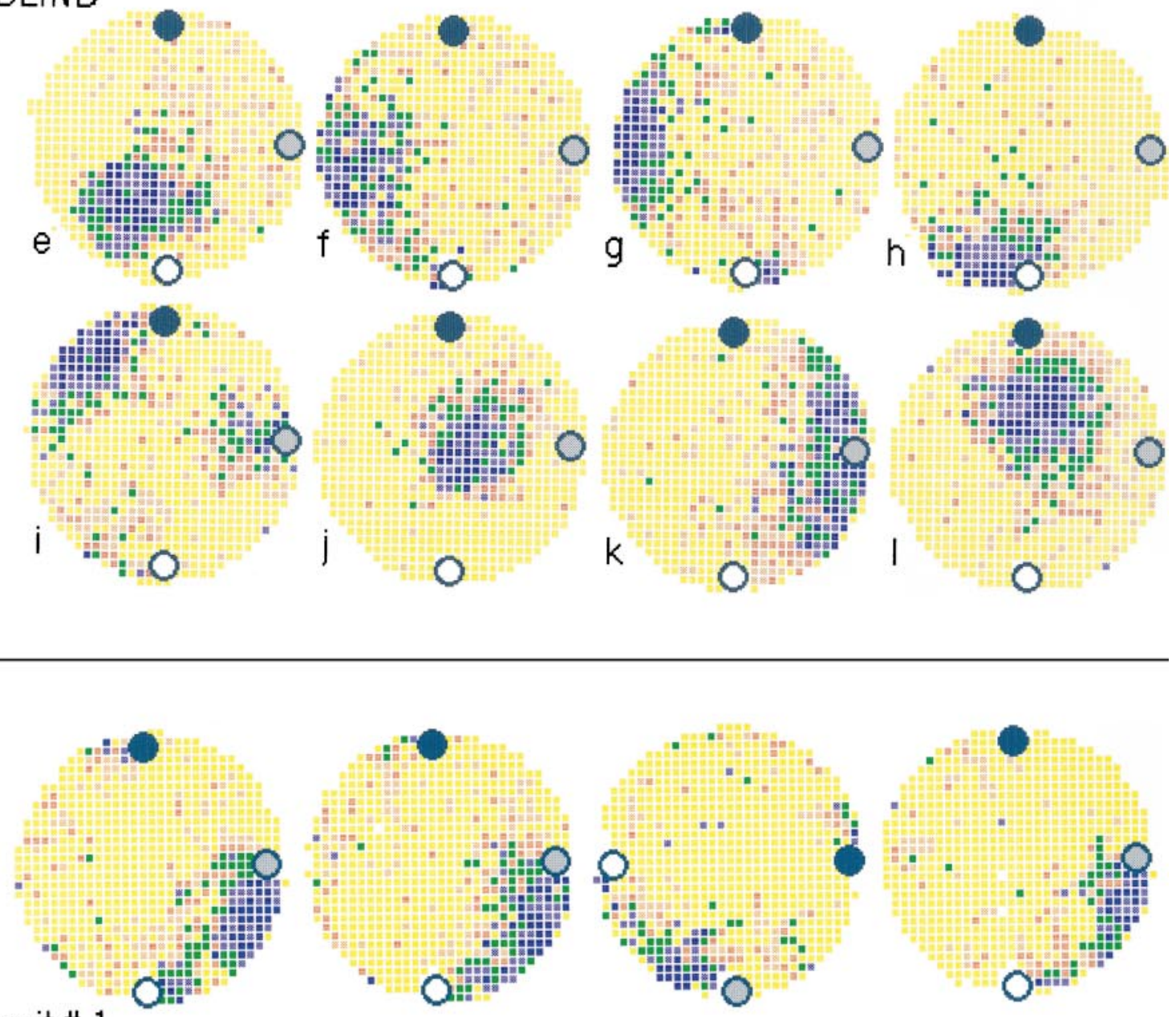

unit \# 1

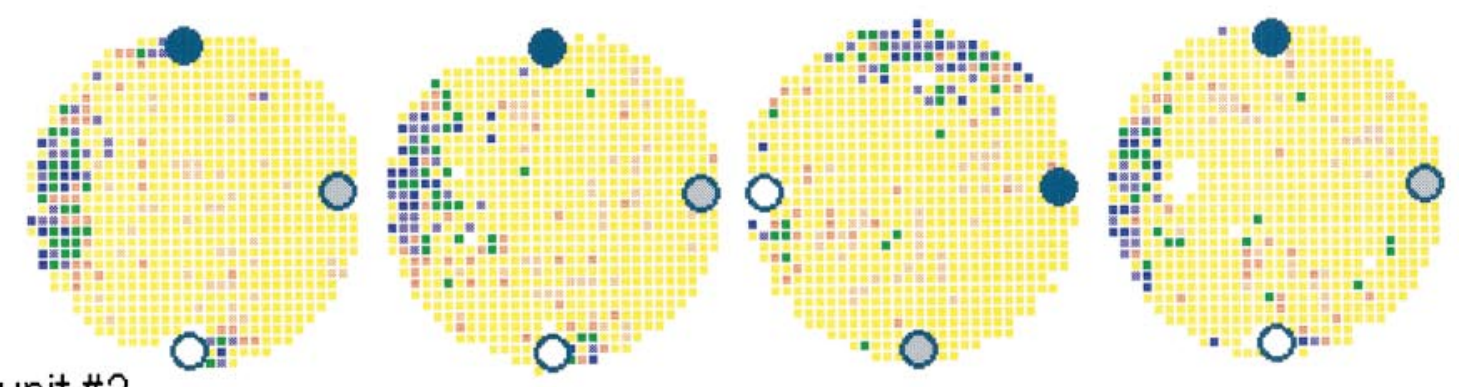

unit \#2 


\begin{tabular}{|c|c|c|c|c|c|c|c|}
\hline & $\begin{array}{l}\text { Positional } \\
\text { information } \\
\text { content }\end{array}$ & $\begin{array}{l}\text { Mean place } \\
\text { field size } \\
\text { (pixels) }\end{array}$ & $\begin{array}{l}\text { Directional } \\
\text { information } \\
\text { content }\end{array}$ & $\begin{array}{l}\text { Mean firing } \\
\text { rate }(\mathrm{Hz})\end{array}$ & $\begin{array}{l}\text { In-field } \\
\text { mean firing } \\
\text { rate }(\mathrm{Hz})\end{array}$ & $\begin{array}{l}\text { In-field } \\
\text { peak firing } \\
\text { rate }(\mathrm{Hz})\end{array}$ & $\begin{array}{l}\text { Mean spike } \\
\text { amplitude } \\
(\mu \mathrm{V})\end{array}$ \\
\hline $\begin{array}{l}\text { Sighted rats } \\
\qquad(n=38 \text { cells })\end{array}$ & $1.76 \pm 0.11$ & $88.1 \pm 6.9$ & $0.32 \pm 0.04$ & $1.42 \pm 0.16$ & $5.11 \pm 0.42$ & $11.51 \pm 1.14$ & $131.1 \pm 11.2$ \\
\hline $\begin{array}{l}\text { Blind rats } \\
\qquad(n=69 \text { cells })\end{array}$ & $1.94 \pm 0.08$ & $75.4 \pm 4.1$ & $0.43^{*} \pm 0.04$ & $0.61^{* *} \pm 0.06$ & $2.49^{* *} \pm 0.15$ & $6.52^{* *} \pm 0.57$ & $130.7 \pm 7.9$ \\
\hline
\end{tabular}

For each measure, values are shown as means \pm SE. The total size of the cylinder was $\sim 725$ pixels. Each pixel was $6.25 \mathrm{~cm}^{2}$.

${ }^{*} * *$ Significant differences between cells from sighted and blind rats: *, $p<0.001 ; * *, p<0.0001$ (two-tailed Student's $t$ tests for independent samples).

\begin{tabular}{|c|c|c|}
\hline & $\begin{array}{l}\text { Place fields } \\
\text { near an object }\end{array}$ & $\begin{array}{l}\text { Place fields } \\
\text { away from objects }\end{array}$ \\
\hline Sighted rats & $67.8 \%$ & $32.2 \%$ \\
\hline Blind rats & $66.2 \%$ & $33.8 \%$ \\
\hline
\end{tabular}

Inspection of the positional firing patterns during the first recording session was used to classify place fields into one of two categories. (1) Place fields near an object had boundaries that touched at least one object. (2) Place fields away from objects had boundaries that touched none of the three objects.

including overall firing rate $(t=4.54 ; \mathrm{df}=105 ; p<0.0001)$, mean rate in the place field $(t=7.63$; df $=105 ; p<0.0001)$, and peak rate in the place field $(t=3.89$; df $=105 ; p<0.0001)$. Because mean spike amplitude was comparable for units recorded from both blind and sighted rats $(t=0.02$; df $=105$; NS; see Table 1$)$, the differential firing rates can be hardly seen as resulting from differences in waveform discrimination (in general, a lower amplitude of unitary waveforms makes it necessary to be more selective about which waveforms are accepted, thereby lowering acceptance rates).

\section{Place field distribution}

Because, in the absence of visual information, place fields are likely to rely more on close investigation of the object landmarks (although some information about their olfactory and other properties can be gathered at some distance), we examined the possibility that place field locations in blind and sighted rats might be differently distributed in space. For example, place fields in blind rats might tend to cluster around the objects more than do those in sighted rats. However, the proportion of place fields with at least one boundary touching an object and of place fields that were away from the objects was not significantly different in blind and sighted rats (chi-square $=0.02$; NS; Table 2).

Last, fields away from the objects in blind rats were as precise as place fields near the objects, as measured by their positional information content (1.94 for both types of fields). Also there was no statistically significant difference in positional information content for fields away from the objects between blind and sighted rats (blind rats, 1.94; sighted rats, $1.78 ; t=0.8$; df $=32$; NS). In short, blindness did not induce hippocampal over-representation of locations near the objects.

\section{Cue control of place fields}

To establish whether the positional firing patterns of place cells in blind rats were controlled by the position of the set of object landmarks in the recording arena, we usually conducted several additional recording sessions (see Materials and Methods). The usual sequence included two sessions with the objects in the standard position relative to the laboratory frame, followed by a rotation session (during which the objects were rotated $90^{\circ}$ clockwise as a rigid set around the center of the cylinder), and finally ending with a session with the object set rotated $90^{\circ}$ counterclockwise (and therefore returned to the initial standard condition).

Twenty-seven place cells from blind rats were recorded for the whole sequence of sessions, and the results were clear-cut. All place fields were found to be stable under stable conditions (i.e., across the first two standard sessions), to rotate by $90^{\circ}$ when the object set was rotated by $90^{\circ}$, and to return back to their original angular location when the object set was moved back to the standard position (Fig. 2).

In all cells, angular positions of place fields were almost ideally controlled by the position of the object set. This is shown in the scatter plots of Figure 3 in which are summarized the results of rotation sessions for the 27 cells recorded for the whole session sequence. The expected angular position of a firing field (plotted on the $x$-axis) was derived by adding the angle of rotation of the three objects to the observed angular position of the firing field for the previous (baseline) session. The $y$-axis was the observed angular position of the fields for the next session. As can be seen in Figure 3, the points all lie along the $45^{\circ}$ line. In addition, the circular correlation coefficients (Batschelet, 1981) for the 27 points were $>0.98$, showing that the position of the object set predicted the angular firing field location with great precision.

On average, the absolute rotation error of cells recorded in blind rats was $<6^{\circ}$ during both the first $-90^{\circ}$ rotation (between sessions 2 and 3 ) and the second $+90^{\circ}$ rotation (between sessions 3 and 4). This was true both for fields that were close to an object (i.e., with at least one boundary touching an object; $n=17$ ) and for fields that were some distance away $(n=10)$. There was no exception to this observation for cells recorded in blind rats, just as there was no exception in cells recorded from sighted rats in a previous study that used an identical arrangement of objects (Cressant et al., 1997). These results show that even in blind rats the object set was used as a polarizing stimulus for the environment.

That the object landmarks were indeed used by the place cell system of blind rats to anchor place field positions was further evidenced by complementary analyses of cell firing during the very first minute of recording sessions. To examine the influence of previous exploration on cell firing, we started some recording sessions at the exact moment when the rat was put on the floor at the center of the cylinder facing a randomly chosen direction. Individual paths were analyzed until the occurrence of firing in the place field was observed. At this time, the analysis was halted. In-field cell firing was counted if the cell fired a short series of action potentials during a single pass through the field (the exact number of action potentials in the series depended on the overall firing activity of the cell but was never fewer than two). Only 
Figure 3. Scatter plots of expected versus observed angular positions of firing fields. $A$, 1st rotation. $B, 2$ nd rotation. Expected angular position of a firing field ( $x$-axis) is derived by adding the amount of object rotation to the observed angular position of the firing field for a baseline session. The observed angular position is plotted on the $y$-axis.
(A) 1st rotation

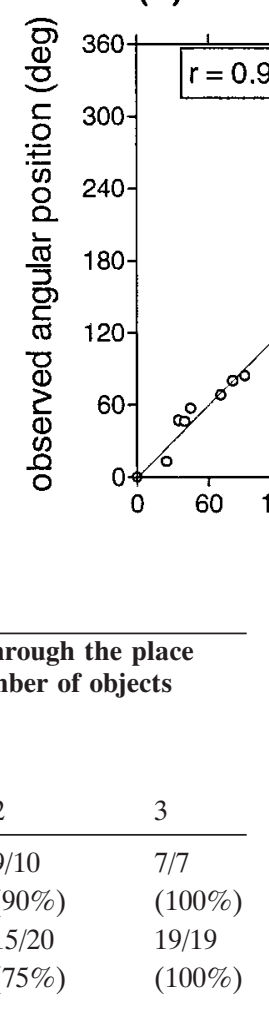

Table 3. Number and proportion of initial passes through the place field resulting in cell firing as a function of the number of objects explored by the rat before cell firing

Number of

\begin{tabular}{lllll} 
objects explored & 0 & 1 & 2 & 3 \\
\hline Sighted rats & $8 / 10$ & $20 / 23$ & $9 / 10$ & $7 / 7$ \\
Blind rats & $(80 \%)$ & $(87 \%)$ & $(90 \%)$ & $(100 \%)$ \\
& $0 / 13$ & $12 / 20$ & $15 / 20$ & $19 / 19$ \\
& $(0 \%)$ & $(60 \%)$ & $(75 \%)$ & $(100 \%)$
\end{tabular}

Because the analysis was halted when the cell was found to fire in the field, only a few passes after visits to two or three objects were counted in sighted rats. A single path could contribute several times to the numbers given in the table if a first (or any subsequent) pass through the field did not result in cell firing.

rotation sessions were examined to eliminate the possibility that in-field cell firing was inadvertently controlled by static background cues rather than by the landmark objects. Also, only the cells with clearly delineated place fields and with mean in-field firing rates of $>1 \mathrm{~Hz}$ were analyzed to remove cells with unreliable firing from the analysis.

The timing of action potentials and their locations were analyzed to relate the first occurrence of cell firing in the place field to the previous behavior of the rat. Specifically, we looked at how many objects had to be investigated by the rat before a pass through the field resulted in cell firing. The results shown in Table 3 indicate that most cells recorded from sighted rats tended to fire from the first moment of entry into the environment. This result strongly suggests that their firing relied on vision of the environment. In contrast, no cell recorded from blind rats was observed to fire in the field when the rat had not made physical contact previously with at least one object. Only $60 \%$ of the cells fired action potentials in the place field after the blind rat had explored one object. All cells were found to fire in the field after the rat had explored all three objects previously (Table 3). The failure of cells to fire before the rat had explored some significant portion of space was discarded as an explanation for the reduced overall firing rates of place cells in blind rats; a simulation of the decrease expected on the basis of the time required by the rat to contact the three objects revealed that this parameter could account only for a $4 \%$ decrease in firing rate, whereas the observed mean firing rates in blind rats were decreased by $>57 \%$.

\section{Behavior}

The results reported above suggest that place cell firing in blind rats depended on previous exploration of the objects. Accord-
(B) 2nd rotation

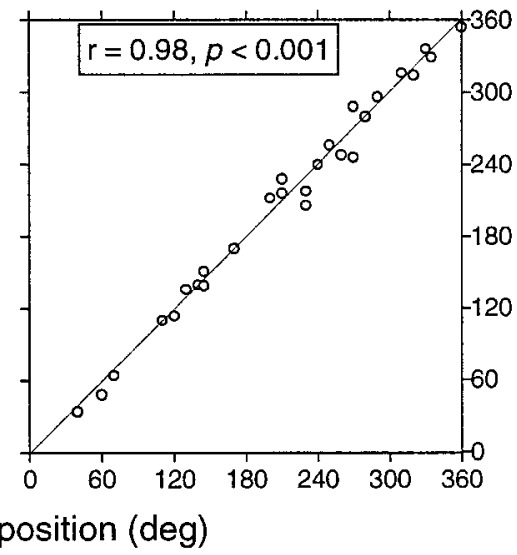

ingly, it was reasonable to look at whether exploratory behavior of blind rats would differ from that of sighted rats. More specifically, we looked at how rats moved in the cylinder and how they made contacts with the objects. These behavioral analyses were conducted only on initial recording sessions so as not to bias the results with other confounding factors. For example, betweengroup differential susceptibility to behavioral fatigue across time might result in different rates of slowing down across sessions for blind and sighted rats.

As expected, blind rats were found to move more cautiously and therefore more slowly in the cylinder than did sighted rats. For each recording session, the change in position of the rat (based on the red LED) was calculated at each $0.5 \mathrm{sec}$ interval, summed over the entire session, and finally divided by the session duration. The results shown in Table 4 show that sighted rats moved faster than did blind rats $(t=3.97$; $\mathrm{df}=87 ; p<0.0001)$. As an aside, we note that this difference in speed might be an explanation for the reduced firing rates of place cells in blind rats. However, the latter hypothesis received little support from additional analyses that were made by looking at place cell firing rates during sessions in which blind rats were moving at motion speeds in the range of the motion speeds observed in sighted rats (10-15 $\mathrm{cm} / \mathrm{sec})$. Even under those circumstances, a significant difference in mean firing rate was still found (blind, $0.52 \pm 0.07 \mathrm{~Hz}$; sighted, $1.36 \pm 0.26 \mathrm{~Hz} ; t=2.76 ; \mathrm{df}=35 ; p<0.01)$, thus suggesting that motion speed was not the major cause of lower place cell firing rates in blind rats.

Object exploration was first measured by accumulating the total time the rat spent in the close vicinity of the objects during the initial recording session. The area for accumulating time was a circular region around each object (set to one pixel around the object). A statistical analysis revealed no tendency for blind rats to spend more time near the objects compared with sighted rats $(t=0.98 ; \mathrm{df}=87$; NS; see Table 4$)$.

The total number of contacts with the objects was also analyzed for each session. To do so, the trajectory of the rat was replayed and superimposed on a map of the apparatus showing the three object locations. The occurrence of a contact with an object was defined as the red light being within one pixel of the object radius (i.e., the snout of the rat actually touching the object) at the end of a path starting elsewhere in the cylinder. Successive contacts to an individual object were counted only if the rat had run a distance corresponding to an arc of $90^{\circ}$ of the apparatus wall (60 $\mathrm{cm}$ ) between each contact. On average, blind rats did not make 
Table 4. Behavioral results

\begin{tabular}{|c|c|c|c|c|c|}
\hline & $\begin{array}{l}\text { Mean speed } \\
(\mathrm{cm} / \mathrm{sec})\end{array}$ & $\begin{array}{l}\text { Object ex- } \\
\text { ploration } \\
\text { time }(\mathrm{sec})\end{array}$ & $\begin{array}{l}\text { Number of } \\
\text { contacts } \\
\text { with objects }\end{array}$ & $\begin{array}{l}\text { Index of } \\
\text { object } \\
\text { contact }\end{array}$ & $\begin{array}{l}\text { Mean duration } \\
\text { of object con- } \\
\text { tact (sec) }\end{array}$ \\
\hline $\begin{array}{l}\text { Sighted rats } \\
\qquad(n=30 \text { sessions })\end{array}$ & $11.95 \pm 0.46$ & $12.4 \pm 1.2$ & $61.4 \pm 2.3$ & $0.55 \pm 0.06$ & $0.21 \pm 0.02$ \\
\hline $\begin{array}{l}\text { Blind rats } \\
\quad(n=59 \text { sessions })\end{array}$ & $9.17^{*} \pm 0.44$ & $14.3 \pm 1.3$ & $64.1 \pm 3.8$ & $0.72 * \pm 0.06$ & $0.2 \pm 0.02$ \\
\hline
\end{tabular}

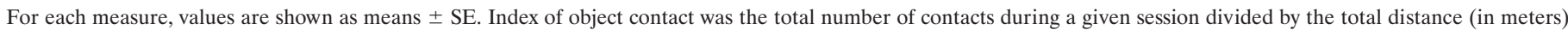

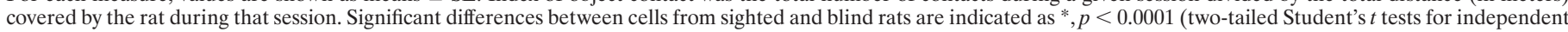
samples).

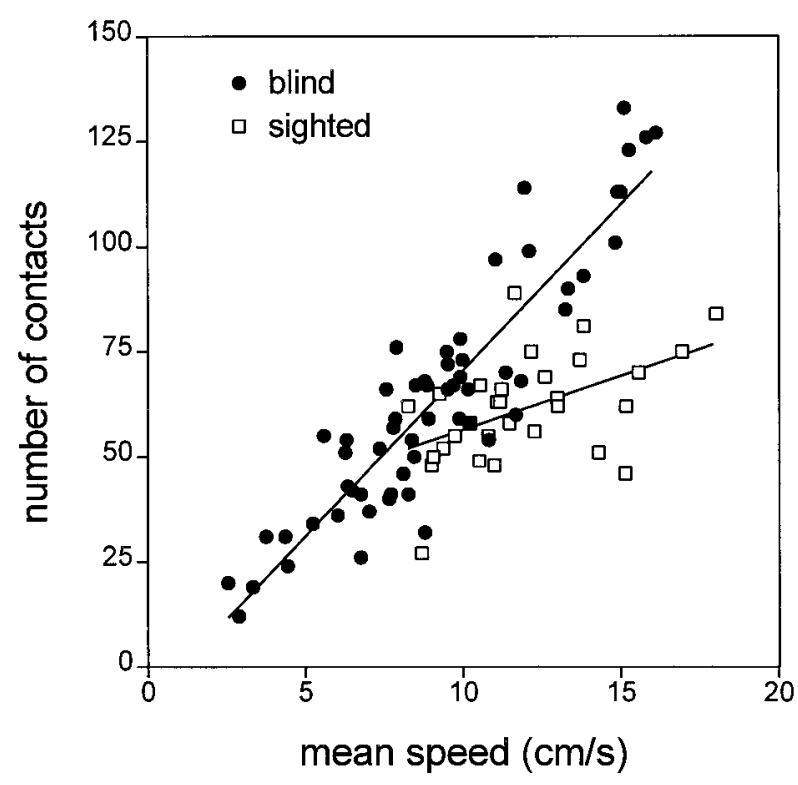

Figure 4. Scatter plot of motion speeds versus numbers of contacts with the objects. In blind rats, the slope of the linear regression line was 7.9, and speed accounted for $84 \%$ of the variance in the number of contacts with the objects. In contrast, the slope was only 2.56 for sighted rats, with speed accounting for $25 \%$ of the variance in the number of contacts with the objects.

more contacts with the objects than did sighted rats $(t=0.47$; $\mathrm{df}=$ 87 ; NS), nor did they spend more time exploring the objects during each contact $(t=0.96$; df $=87$; NS; see Table 4).

Because the number of contacts possibly made during a session depended on the speed of motion of the rat (Fig. 4), an index was calculated by dividing the total number of contacts during a given session by the total distance (in meters) covered by the rat during that session to take into account the lower speeds of blind rats. This index was found to be greater in blind rats as compared with sighted rats $(t=6.09$; df $=87 ; p<0.0001$; see Table 4$)$, showing that, for trajectories of similar length, blind rats made more contacts with the objects than did sighted rats. Figure 4 clearly shows the relation between the speed of the rat and the number of contacts with the objects. There was a clear difference in slopes between blind and sighted rats (blind, slope $=7.9$ and $R^{2}=0.84$; sighted, slope $=2.56$ and $\left.R^{2}=0.25\right)$, suggesting that the increase in the number of contacts as a function of the speed of the rat was markedly greater in blind rats than in sighted rats.

\section{DISCUSSION}

Our results indicate that in spite of early blindness, the rat hippocampal system contains fully functional place cells. Overall the characteristics of these cells do not seem to make them different from place cells recorded from sighted rats under identical circumstances. The positional firing properties of place cells recorded from blind rats were very similar to those of place cells recorded from sighted rats, and if firing rate was ignored, place cells from blind and sighted rats were virtually indistinguishable.

One major deviation from this similarity concerns firing rates that were markedly lower in cells from blind rats. Because spike parameters were very similar for cells recorded from both blind and sighted rats, these lower rates cannot be attributed to some recording bias caused by differential adjustment of window parameters during recording. Also, the hypothesis that cells from blind rats were discharging at lower rates because these rats needed to contact objects before the first occurrence of firing in the field was discarded as a likely explanation. Last, because previous data suggest the existence of a positive relation between the instantaneous velocity of the animal and the firing activity of place cells (McNaughton et al., 1983), the difference in average motion speed that was found between blind and sighted rats in the present study was examined as a possible explanation of the lower firing rates of place cells in blind rats. Although this hypothesis is attractive, it received little support from additional analyses that looked at place cell firing rates in blind rats during sessions in which they moved at average speeds similar to those of sighted rats. Even under those circumstances, lower firing rates were found in blind rats. Finally, a possible, although speculative, explanation relies on the fact that location-specific activation of hippocampal place cells normally relies on convergent excitatory inputs from several sensory systems including vision, proprioception, and vestibular information (McNaughton et al., 1996). In the absence of visual input, activation of hippocampal place cells relies on a reduced number of sensory sources. If one assumes that activation of a given place cell is triggered by the total net amount of excitatory and inhibitory activities it receives (with such activities being determined as well by the sensory information reaching the hippocampus), then the observed decrease in place cell firing rates in blind rats might result from the reduced amount of excitatory inputs. An alternative version of this hypothesis would be that inhibitory modulation by local interneurons ( $\theta$ cells; see Fox and Ranck, 1981) would be increased. Unfortunately, because no attempt was made to record $\theta$ cells in the present study, it is difficult at present to provide support for the latter hypothesis.

As seen in sighted rats (Cressant et al., 1997), place cells in blind rats were demonstrated to use three-dimensional objects intentionally placed into the recording cylinder as spatial landmarks. This was shown by the almost ideal control exerted by the object set on place field locations. Rotation of the objects was followed by equivalent rotation of place fields. The ability of the 
place cell system to use the objects as landmarks implies knowledge of their positions. Because such knowledge cannot be acquired at a distance by blind rats (contrary to sighted rats who can "sample" the environment visually), it was expected that cell firing would depend on previous exploratory behavior of the rat.

Clear support for this hypothesis was provided by additional analyses that revealed that, contrary to place cells in sighted rats, no cell in blind rats was observed to fire in the firing field if the rat had not made physical contact with an object previously. In many cells recorded from blind rats, knowledge of one landmark position was enough to activate firing in the place field. This confirms that, to produce coherent firing, the hippocampal place cell system needs information about the location of objects. This result additionally suggests that the system is able to use the intrinsic (e.g., olfactory, tactile) properties of objects to recognize which object the animal has encountered. However, the fact that in-field cell firing was seen more often after the rat had explored several objects also suggests that reliability of spatial localization was increased when further exploration confirmed the geometrical stability of the environment (Poucet et al., 1986; Gallistel, 1990; Biegler and Morris, 1996; O'Keefe and Burgess, 1996).

Because place fields were also found at locations that were some distance away from the objects, one must imagine that the system is able to compute a position everywhere in the environment and not just at object locations. One possibility is that, once landmark positions are known, the place cell system relies on the dynamic use of internally generated, motion-related information to update the position of the system throughout the environment. Such information includes kinesthetic signals from the vestibular system, proprioceptive cues, and motor efference copy signals (McNaughton et al., 1996). Although motion-related signals are known to accumulate errors across successive movements in space, such errors can be corrected at each contact with an object by using the fixed object locations as a means for recalibrating a calculated position. In our experiment, this process is likely to occur many times during a recording session because of the combined effects of the small size of the cylinder and of the number of objects. Clear behavioral evidence was found in support of this hypothesis. In fact, detailed analyses of exploratory patterns revealed that blind rats tended to make exploratory contacts with the objects more often than did sighted rats. Such a pattern of exploration is highly suggestive of a compensatory strategy the result of which is to provide blind rats with additional spatial information allowing them to recalibrate their position in the arena.

In conclusion, our data provide evidence that, although they can be anchored by visual information when such is available (Muller and Kubie, 1987; Quirk et al., 1990; Sharp et al., 1990), place cells also receive strong inputs from motion-related systems and other nonvisual modalities (e.g., tactile) that are sufficient to trigger spatially coherent firing. In addition, place cell locationspecific firing does not seem to depend on early visual experience because it was observed in rats that had never seen their environment.

The latter observation leads us to make a last point relating to the observation that early visual deprivation in animals and humans induces behavioral deficits in many spatial tasks (Tees and Midgley, 1978; Dale and Innis, 1980; Lockman et al., 1981; Tees et al., 1981, 1990; Dodds et al., 1982; Tees, 1990). This issue has been controversial, however, because some studies report very little impairment after visual deprivation (e.g., Lindner et al., 1997; for thorough discussions of human data, see Strelow, 1985;
Thinus-Blanc and Gaunet, 1997). At any rate, our study suggests that the spatial impairments of blind animals, if any, are not the consequence of a decreased ability of the hippocampal place cell system to keep track of movements in space. Whether such sparing in location-specific firing of hippocampal place cells would still be observed had blindness occurred at a later developmental stage cannot be appreciated at present. Evidence from a previous study indicates that the spatial reliability of place cell firing in sighted rats is decreased in the dark relative to normal lighting conditions (Markus et al., 1994). However, several methodological differences [e.g., in the study of Markus et al. (1994), rats could see the environment before the lights were turned out, and a disorientation procedure was used before each entry into the experimental room] preclude drawing any strong conclusion. Therefore, the idea that the unaltered spatial firing patterns in the blind rats of the present study might result from early adaptation to the absence of vision will require further research.

\section{REFERENCES}

Batschelet E (1981) Circular statistics in biology. London: Academic.

Biegler R, Morris RGM (1996) Landmark stability: studies exploring whether the perceived stability of the environment influences spatial representation. J Exp Biol 119:187-193.

Cressant A, Muller RU, Poucet B (1997) Failure of centrally placed objects to control the firing fields of hippocampal place cells. J Neurosci $17: 2531-2542$.

Dale RHI, Innis NK (1980) Spatial memory without vision: radial maze performance of blind rats. Univ Western Ontario Res Bull 523.

Dodds AG, Howarth CI, Carter DC (1982) The mental maps of the blind: the role of previous visual experience. J Vis Impairment Blindness 76:5-12.

Etienne AS, Maurer R, Séguinot V (1996) Path integration in mammals and its interaction with visual landmarks. J Exp Biol 119:201-209.

Fox SE, Ranck Jr JB (1981) Electrophysiological characteristics of hippocampal complex-spike cells and theta cells. Exp Brain Res 41:399-410.

Gallistel C (1990) The organization of learning. Cambridge, MA: MIT.

Gothard KM, Skaggs WE, McNaughton BL (1996) Dynamics of mismatch correction in the hippocampal ensemble code for space: interaction between path integration and environmental cues. J Neurosci 16:8027-8040.

Hill B, Best P (1981) Effects of deafness and blindness on the spatial correlates of hippocampal unit activity in the rat. Exp Neurol $74: 204-217$

Kubie, JL (1984) A driveable bundle of microwires for collecting singleunit data from freely moving rats. Physiol Behav 32:115-118.

Lindner MD, Plone MA, Schallert T, Emerich DF (1997) Blind rats are not profoundly impaired in the reference memory Morris water maze and cannot be clearly discriminated from rats with cognitive deficits in the cued platform task. Cognit Brain Res 5:329-333.

Lockman JJ, Rieser JJ, Pick HL (1981) Assessing blind travelers' knowledge of spatial layout. J Vis Impairment Blindness 75:321-326.

Markus EJ, Barnes CA, McNaughton BL, Gladden VL, Skaggs WE (1994) Spatial information content and reliability of hippocampal CA1 neurons: effect of visual input. Hippocampus 4:410-421.

McNaughton BL, Barnes CA, O'Keefe J (1983) The contributions of position, direction, and velocity to single unit activity in the hippocampus of freely-moving rats. Exp Brain Res 52:41-49.

McNaughton BL, Chen LL, Markus EJ (1991) "Dead reckoning", landmark learning, and the sense of direction: a neurophysiological and computational hypothesis. J Cognit Neurosci 3:190-202.

McNaughton BL, Barnes CA, Gerrard JL, Gothard K, Jung MW, Knierim JJ, Kudrimoti H, Qin Y, Skaggs WE, Suster M, Weaver KL (1996) Deciphering the hippocampal polyglot: the hippocampus as a path integration system. J Exp Biol 119:173-185.

Mittelsteadt H (1983) The role of multimodal convergence in homing by path integration. Fortsch Zool 28:197-212.

Mittelsteadt ML, Mittelsteadt H (1980) Homing by path integration in a mammal. Naturwissenschaften 67:566-567.

Muller RU (1996) A quarter of century of place cells. Neuron 17:813-822. 
Muller RU, Kubie JL (1987) The effects of changes in the environment on the spatial firing of hippocampal complex-spike cells. J Neurosci 7:1951-1968.

Muller RU, Kubie JL, Ranck Jr JB (1987) Spatial firing patterns of hippocampal complex-spike cells in a fixed environment. J Neurosci 7:1935-1950.

Muller RU, Bostock EM, Taube JS, Kubie JL (1994) On the directional firing properties of hippocampal place cells. J Neurosci 14:7235-7251.

Nadel L (1991) Forum: is the hippocampal formation preferentially involved in spatial behavior? Hippocampus 1:221-292.

O'Keefe J (1976) Place units in the hippocampus of the freely moving rat. Exp Neurol 51:78-109.

O'Keefe J, Burgess N (1996) Geometric determinants of the place fields of hippocampal neurons. Nature 381:425-428.

O'Keefe J, Dostrovsky J (1971) The hippocampus as a spatial map. Preliminary evidence from unit activity in the freely moving rat. Brain Res 34:171-175.

O'Keefe J, Nadel L (1978) The hippocampus as a cognitive map. Oxford: Clarendon.

O'Keefe J, Speakman A (1987) Single unit activity in the rat hippocampus during a spatial memory task. Exp Brain Res 68:1-27.

Paxinos G, Watson C (1986) The rat brain in stereotaxic coordinates. New York: Academic.

Poucet B (1993) Spatial cognitive maps in animals: new hypotheses on their structure and neural mechanisms. Psychol Rev 100:163-182.

Poucet B, Benhamou S (1997) The neuropsychology of spatial cognition in the rat. Crit Rev Neurobiol 11:101-120.

Poucet B, Chapuis N, Durup M, Thinus-Blanc C (1986) A study of exploratory behavior as an index of spatial knowledge in hamsters. Anim Learn Behav 14:93-100.

Quirk GJ, Muller RU, Kubie JL (1990) The firing of hippocampal place cells in the dark depends on the rat's recent experience. J Neurosci 10:2008-2017.

Sharp PE, Kubie JL, Muller RU (1990) Firing properties of hippocampal neurons in a visually symmetrical environment: contributions of multiple sensory cues and mnemonic processes. J Neurosci 10:3093-3105.

Sharp PE, Blair HT, Etkin D, Tzanetos DB (1995) Influences of vestibular and visual motion information on the spatial firing patterns of hippocampal place cells. J Neurosci 15:173-189.

Skaggs WE, McNaughton BL, Gothard KM, Markus EJ (1993) An information-theoretic approach to deciphering the hippocampal code. In: Advances in neural information processing 5 (Hanson SJ, Cowan JD, Giles CL, eds), pp 1030-1037. San Mateo, CA: Morgan Kaufman.

Strelow ER (1985) What is needed for a theory of mobility: direct perception and cognitive maps. Lessons from the blind. Psychol Rev 92:226-248.

Taube JS, Muller RU, Ranck Jr JB (1990) Head-direction cells recorded from the postsubiculum in freely moving rats. I. Description and quantitative analysis. J Neurosci 10:420-435.

Tees RC (1990) The effect of early experience on water maze spatial learning and memory in rats. Dev Psychobiol 23:427-439.

Tees RC, Midgley G (1978) Extent of recovery of function after early sensory deprivation in the rat. J Comp Physiol Psychol 92:742-751.

Tees RC, Midgley G, Nesbit JC (1981) The effect of early visual experience on spatial maze learning in rats. Dev Psychobiol 14:425-438.

Tees RC, Buhrmann K, Hanley J (1990) Experience, perceptual competences, and rat cortex. In: The cerebral cortex of the rat (Kolb B, Tees RC, eds), pp 507-536. Cambridge, MA: MIT.

Thinus-Blanc C, Gaunet F (1997) Space representation in the blind: vision as a spatial sense? Psychol Bull 121:20-42. 